\title{
Development of Copper Hatch Baskets and Evaluation of the Productive Indexes of a Commercial Hatchery
}

\author{
Ronise Faria Rohde Depner', Vivian Lucca', Rômulo Alexandre Depner', Karine Patrin Pontin ', Luciana \\ Pötter', Karen Apellanis Borges ${ }^{2}$, Thales Quedi Furian², Vladimir Pinheiro do Nascimento² \& Maristela Lovato'
}

\begin{abstract}
Background: The dissemination of pathogenic microorganisms in hatcheries leads to a higher number of contaminated eggs, causing reduction in hatchability and increase of discarded chicks. Sanitation programs are crucial for maximum hatchability and chick quality. Efforts have been made to find alternative approaches to the conventional disinfectants, and surfaces with copper, which have antimicrobial properties, could assist in this process. However, the possible adverse effects of copper surfaces on chicks in hatcheries have not yet been evaluated. The present study aimed at developing hatch baskets composed of copper and evaluating the effect of these baskets on the productive indexes of a hatchery.

Materials, Methods \& Results: For this experiment, $3.15 \mathrm{~kg}$ hatch tray prototypes with $99.9 \% \mathrm{Cu}(\mathrm{Cu} 11000)$ were developed to fit inside conventional polypropylene hatch baskets $(580 \times 755 \times 83 \mathrm{~mm})$. Six polypropylene hatch baskets (control group) and six polypropylene hatch baskets covered by $99.9 \%$ copper (Cu11000) hatch trays (test group) were evaluated during 5 hatchings. Hatched eggs and chicks remained in contact with the hatch basket surfaces for at least 72 $\mathrm{h}$, corresponding to the entire period in which they were located in the hatcher. Cleaning and disinfection programs of the hatchery were not modified. The level of microbial contamination on the hatch baskets was evaluated at 6 different periods: $0 \mathrm{~h}$ (initial contamination after disinfection and egg transfer to the trays); $24 \mathrm{~h}, 30 \mathrm{~h}, 45 \mathrm{~h}$ and $60 \mathrm{~h}$ after the first sampling; and at the moment when chicks were removed from the hatching cabinet and transferred to the chick-holding room $(>60$ h). Counting of total moulds and yeasts, mesophilic microorganisms, Enterobacteria and Escherichia coli colonies was performed. The number of hatched chicks, non-hatched eggs, and chicks discarded were registered for each hatching. Microbiologic analyses showed no growth on hatch baskets neither of the test group nor on those of the control group, regardless of the period evaluated. No significant difference was found between the two groups in the counts of hatched chicks, non-hatched eggs, and chicks discarded.

Discussion: The antimicrobial efficacy of copper surfaces has been established for a variety of bacteria and fungi, including in the healthcare environment. In addition, antimicrobial resistance to copper is extremely rare because of copper's multisite kill mechanism and other mostly nonspecific damage mechanisms. Several copper applications have been established; however, the potential adverse effects of using copper surfaces in hatcheries on chicks or on hatchery productive indexes had not yet been evaluated. The analyses performed in this study did not show microbiological growth. The results showed that the copper surface did not cause any significant adverse effects on chicks. The hatched chicks were visually healthy, and no significant difference was found between the numbers of chicks discarded in the control and test groups. Since the production parameters were not altered or impaired in the present study, it is possible to conclude that the use of copper surfaces in hatcheries can be an effective tool in the microbiological control of these environments. Nevertheless, copper alloys lend themselves to the creation of self-sanitizing surfaces that should be used as a complement and not as a substitute for standard cleaning and disinfection practices.
\end{abstract}

Keywords: copper, hatchery, microbiological control, safety, poultry. 
R.F.R. Depner, V. Lucca, R.A. Depner, et al. 2020. Development of Copper Hatch Baskets and Evaluation of the Productive

\section{INTRODUCTION}

The dissemination of pathogenic microorganisms in hatcheries leads to a higher number of contaminated eggs, reducing hatchability and increasing the number of discarded chicks [8]. Microorganisms found on or in a few eggs can be easily disseminated throughout a hatching cabinet by air movement during hatching, contaminating other chicks in the same environment [23]. Formaldehyde has been used as a fumigant or disinfectant in many hatcheries for controlling microorganisms. Other moderately effective disinfectants such as quaternary ammonium compounds, peroxides, glutaraldehyde, phenolics, acetic acid, chlorine, and iodine derivatives are also used in the poultry industry $[8,21]$. Washing and sanitizing chicken transport cages reduce bacterial contamination on the flooring surface, but they do not completely eliminate the problem [17]. Moreover, there are many restrictions on the use of disinfectants compounds [16,20].

An alternative for the microbiological control of the hatchery environment is using copper surfaces. The U.S. Environmental Protection Agency approved the registration of copper alloys as materials with antimicrobial properties [7]. The antimicrobial activity of copper surfaces against several pathogens has already been demonstrated $[2,4,6,19]$. Therefore, different areas of the poultry production chain, including hatcheries, could benefit from the application of copper on surfaces. However, the relationship of copper contact surfaces with the production indexes of hatcheries remains unknown.

In this context, the present study aimed at developing hatch baskets composed of copper and evaluating the effect of these baskets on the productive indexes of a hatchery.

\section{MATERIALS AND METHODS}

\section{Local description}

The experiment was conducted in a commercial poultry hatchery located in the Santa Catarina state, Southern Brazil. This hatchery produces an average of 1,000,000 1-day-old chicks per month, using 9 conventional incubators with multi-stage operation and nine hatching cabinets. The machines ${ }^{1}$ operate with incubator trays with capacity for 150 eggs. Eggs were transferred from the setter to the hatcher always on the 18th day of incubation. The standard temperature of incubators was $37.3-37.5^{\circ} \mathrm{C}$, and the humidity was maintained at $84 \%$.

\section{Copper hatch baskets}

For this experiment, $3.15 \mathrm{~kg}$ hatch tray prototypes with $99.9 \% \mathrm{Cu}(\mathrm{Cu} 11000)$ were developed to fit inside conventional polypropylene hatch baskets (580 $\times 755 \times 83 \mathrm{~mm}$ ) [Figure $1 \mathrm{~A} \& 1 \mathrm{~B}$ ]

\section{Experimental design}

A total of 5 hatchings were evaluated in this experiment. In each hatching, 6 polypropylene hatch baskets (control group) and 6 polypropylene hatch baskets covered with the copper prototype (test group) were distributed in a paired way in 3 different positions (upper, intermediate, and lower level) of the same column of a trolley. Hatched eggs and chicks remained in contact with the hatch basket surfaces for at least $72 \mathrm{~h}$, corresponding to the entire period in which they were located in the hatcher. The cleaning and disinfection programs of the hatchery were not modified, including the standard hygiene protocols of the hatch baskets used in this experiment.

\section{Microbial analysis and productive parameters selected}

The level of microbial contamination on the hatch baskets was evaluated at 6 different periods: $0 \mathrm{~h}$ (initial contamination after disinfection and egg transfer to the trays); $24 \mathrm{~h}, 30 \mathrm{~h}, 45 \mathrm{~h}$ and $60 \mathrm{~h}$ after the first sampling; and at the moment when chicks were removed from the hatching cabinet and transferred to the chick-holding room $(>60 \mathrm{~h})$. For the microbial analysis, the bottom of each hatch basket was sampled with a swab soaked in $0.9 \%$ sterile saline solution in a $25 \mathrm{~cm}^{2}$ area delimited by a sterile metal model. The samples were stored in sterile bags and refrigerated for laboratory analysis. The enumeration of total moulds and yeasts, mesophilic microorganisms, and Enterobacteria and Escherichia coli colonies was performed according to the guidelines of the Normative Instruction 62 of the Brazilian Ministry of Agriculture, Livestock and Supply (MAPA) [3], and the results were expressed as Colony Forming Units per Square Centimetre $\left(\mathrm{CFU} / \mathrm{cm}^{2}\right)$. The following productivity indices for each hatch basket in the control and test groups were registered: hatched chicks, non-hatched eggs, and discarded chicks (dead or eliminated).

\section{Statistical analysis}

All procedures were performed with 30 repetitions (trays) for each treatment in the 5 hatchings. The Student-Newman-Keuls test was performed to examine the statistical significance of the results. The Statistical Analysis Software ${ }^{2}$ was used for the analyses, at a significance level of $5 \%$. 


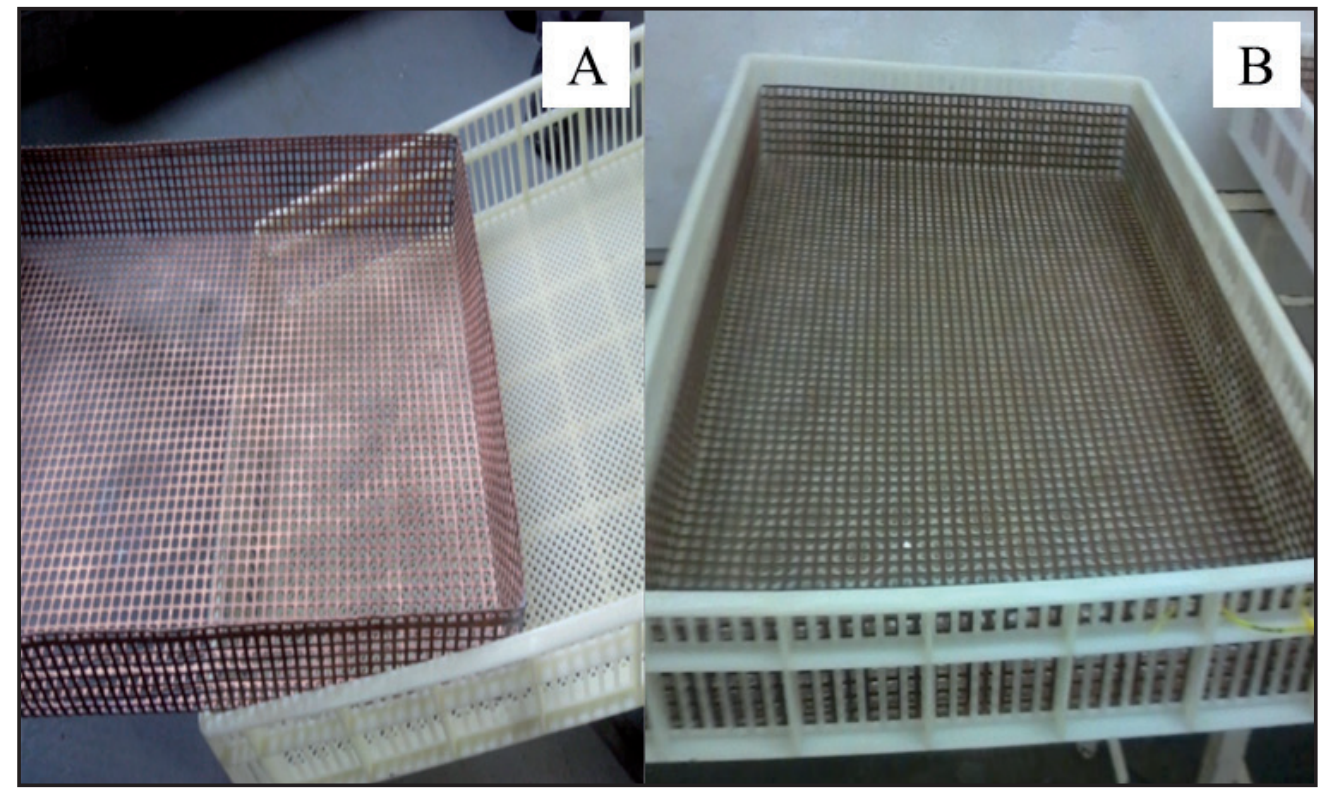

Figure 1. A- Copper hatch basket prototype developed for the experiment: fitted apart. B- Prototype attached to the conventional polypropylene hatch basket.

Table 1. Hatchery productive indexes (hatched chicks, non-hatched eggs and chicks discarded), according to the treatment in the hatchery.

\begin{tabular}{|c|c|c|c|}
\hline Treatment & Average hatched chicks & $\begin{array}{l}\text { Average non-hatched } \\
\text { eggs (mean) }\end{array}$ & $\begin{array}{l}\text { Chicks discarded (dead or } \\
\text { eliminated) }\end{array}$ \\
\hline $\begin{array}{l}\text { polypropylene hatch basket } \\
\text { (control group) }\end{array}$ & 126.97 & 1.20 & 21.50 \\
\hline $\begin{array}{l}\text { hatch baskets composed of copper } \\
\text { (test group) }\end{array}$ & 127.20 & 1.27 & 21.53 \\
\hline$P$-value ${ }^{\mathrm{a}}$ & 0.9587 & 0.9261 & 0.8646 \\
\hline
\end{tabular}

${ }^{a}$ Student-Newman-Keuls test $(P>0.05)$.

\section{RESULTS}

The microbiologic analysis for total moulds and yeasts, mesophilic microorganisms, and Enterobacteria and Escherichia coli colonies showed no colony growth on hatch baskets of the test group (n $=30)$ nor on those of the control group $(\mathrm{n}=30)$, regardless of the period evaluated. Hatchery productive indexes for the 2 groups are described in Table 1. No significant difference $(P>0.05)$ was found between the 2 groups in the counts of hatched chicks, non-hatched eggs, and chicks discarded.

\section{DISCUSSION}

Hygiene is an important aspect of hatchery design and management. A good sanitation program is crucial for maximum hatchability and chick quality $[8,21]$. Moreover, the incidence of certain diseases in poultry farms is directly related to the hatcheries' health programs [21]. Setter and hatcher rooms are primary sources of contamination, and tray washes or outside/waste areas have the highest probability of being contaminated [14]. For instance, the use of mouldy litter or the introduction of 1-day-old birds with fungal propagules in hatchery facilities is related with the occurrence of aspergillosis in poultry farms [1]. In this context, formaldehyde has been one of the most widely used disinfectants in hatcheries, especially because of its low cost, high availability, effectiveness against a large variety of microorganisms, and noncorrosive effects [20]. However, European Union authorities have recently regulated the use of formaldehyde as it has been proven to be carcinogenic [11]. In addition, pre-incubation fumigation with formaldehyde may affect the tracheal epithelial cells of 18-day-old embryos and 1-day-old chicks, causing ciliostasis and 
abnormal morphology [10,11]. Thus, substantial efforts have been made to find alternative approaches for hatchery hygiene, and the use of copper surfaces may assist in this process $[11,22]$.

The antimicrobial efficacy of copper surfaces has been established for a variety of bacteria and fungi, including in the healthcare environment $[4,5,6,18,19,22]$. Antimicrobial resistance to copper is extremely rare because of copper's multisite kill mechanism and other mostly nonspecific damage mechanisms [2]. The release of copper ions from the metal surface causes severe damage to bacterial envelopes, loss of membrane potential and cytoplasmic solutes, massive influx of copper ions into the cell interior, oxidative damage to cell constituents, and DNA degradation [13]. Copper has been recognized as a biocide for centuries [2]. Several copper applications have been evaluated, including in drinking water distribution systems, agriculture, animal farming, and healthcare environments [6,22]. However, the potential adverse effects of using copper surfaces in hatcheries on chicks or on hatchery productive indexes had not yet been evaluated.

In order to evaluate the effect of copper surfaces on hatchery productive indexes, we developed a hatch basket prototype for this study. As the antimicrobial action of copper occurs when it is in contact with bacteria, releasing ionic copper [22], the first prototype was a $99.9 \% \mathrm{Cu}$ whole plate placed at the bottom of conventional polypropylene hatch baskets. However, the absence of orifices probably resulted in a high accumulation of organic matter (fluff, eggshell, blood, and meconium) on the copper surface, which in turn led to reduced copper antimicrobial activity (data not shown). Protein or carbohydrate compounds probably interact and act like copper chelating complexes that prevent or delay the activity of copper over cell membranes [19]. Moreover, hatch baskets without orifices make it difficult for chicks to have balance on a smooth surface, leading to inability to move and standing on open legs, which would result in the chicks discard. For all these reasons, a new prototype was designed, with a surface with orifices suitable for the balance of the hatched chicks. The first project foresaw a hatch basket composed entirely of copper. However, this basket would weigh approximately $11 \mathrm{~kg}$, which is extremely heavy when compared to the $3.15 \mathrm{~kg}$ of the prototype used in study. Routine hatchery management and procedures are not compatible with excessively heavy tools. The stacking of trays inside the trolleys, for instance, would be impossible.

In the course of hatchings and cleaning procedures in the experiment, the surface of the hatch baskets oxidized and tarnished, which was expected. The copper tarnish film may more readily release $\mathrm{Cu}^{+2}$ than a bright metal surface [15]. However, a thick copper oxide layer lowers the antimicrobial effectiveness of copper surfaces $[6,9]$. Despite the tarnishing observed, there was no increase of copper oxide on the hatch baskets in this study.

Until now, there are no studies evaluating the effect of chicks contact with copper surfaces in the productive indexes of commercial hatcheries. The analyses performed in this study did not show microbiological growth. This result was not expected because of the high amount of contaminants that are present in these environments [12]. A total of $80 \mathrm{~mL}$ of formaldehyde per machine is used every $4 \mathrm{~h}$, and this constant decontamination process probably eliminated or reduced to uncountable levels the contamination present on the surfaces in both groups over the incubation time. Nevertheless, a previous study demonstrated the in vitro antimicrobial efficacy of copper against bacteria and fungi isolated from commercial poultry hatcheries [5]. Moreover, copper and copper alloys are self-sanitizing surfaces that should be used as a complement to hygiene control, but not as substitute for standard cleaning and disinfection of surfaces $[7,13,15]$.

The results showed that the copper surface did not cause any significant adverse effects on chicks. The hatched chicks were visually healthy, and no significant difference $(P>0.05)$ was found between the numbers of chicks discarded in the control and test groups. Likewise, copper did not negatively influence the number of non-hatched eggs between the groups. These observations corroborate the measures of the U.S. Environmental Protection Agency (EPA), which considers copper contact surfaces safe and with no risk to public health despite their high toxicity to microorganisms through different mechanisms [2,7]. Simultaneous multisite kill mechanisms of copper may be acting to reduce the ability of microorganisms to develop resistance to copper $[2,15]$. Thus, the re-assessment of the benefits of antimicrobial copper follows a proliferation of multiple antibiotic resistant and disinfectant-resistant bacterial strains [6]. The many applications of copper in the battle against pathogens may have advantages and will probably result in an increased demand for copper products. 
R.F.R. Depner, V. Lucca, R.A. Depner, et al. 2020. Development of Copper Hatch Baskets and Evaluation of the Productive

The copper hatch basket prototype did not interfere in the productive indexes herein evaluated, which demonstrates that it may be a safe contact surface. Considering copper's recognized antimicrobial activity, these hatch baskets can be used to complement the hygiene program in this type of poultry environment.

\section{CONCLUSION}

The results indicate that the use of copper surfaces in hatcheries can be an effective tool in the microbiological control of these environments. Nevertheless, copper alloys lend themselves to the creation of self-sanitizing surfaces that should be used as a complement and not as a substitute for standard cleaning and disinfection practices.

\section{MANUFACTURERS}

${ }^{1}$ Coopermaq Máquinas e Equipamentos. Urussanga, SC, Brazil.

${ }^{2}$ SAS Institute. Cary, NC, USA.

Funding. Project financed by the Brazilian Copper Institute.

Acknowledgements. The authors thank Porto Belo Laboratory for the microbiological analyses and Mr. Antoninho Casarin for his assistance in carrying out the project.

Ethical approval. This experiment and all procedures were approved by the Ethics Committee on Animal Use of the Federal University of Santa Maria (UFSM), under protocol number 130/2014.

Declaration of interest. The authors report no conflicts of interest. The authors alone are responsible for the content and writing of paper.

\section{REFERENCES}

1 Arné P., Thierry S., Wang D., Deville M., Le Loc'h G., Desoutter A., Féménia F., Nieguitsila A., Huang W., Chermette R. \& Guillot J. 2011. Aspergillus fumigatus in Poultry. International Journal of Microbiology. 1-14. https:// doi.org/10.1155/2011/746356

2 Borkow G. \& Gabbay J. 2009. Copper, an ancient remedy returning to fight microbial, fungal and viral infections. Current Chemical Biological. 3(3): 272-278.

3 Brazil. 2003. Instrução Normativa $n^{\circ}$ 62, de 26 de agosto de 2003: Oficializa os Métodos Analíticos Oficiais para Análises Microbiológicas para Controle de Produtos de Origem Animal e Água. - Ministério da Agricultura, Pecuária e Abastecimento. Diário Oficial da União, Brasília, DF, 18 set. 2003, Seção1, p.14.

4 Depner R.F.R., Depner R.A., Lucca V. \& Lovato M. 2015. O cobre como superfície de contato antimicrobiana e sua potencial aplicação na Medicina Veterinária. Veterinária e Zootecnia. 22(4): 532-543.

5 Depner R.F. R., Pontin K.P., Depner R.A., Flores Neto A., Lucca V. \& Lovato M. 2016. Action of antimicrobial copper on bacteria and fungi isolated from commercial poultry hatcheries. Brazilian Journal of Poultry. 18(2): 95-97.

6 Elguindi J., Hao X., Lin Y., Alwathnani H.A., Wei G. \& Rensing C. 2011. Advantages and challenges of increased antimicrobial copper use and copper mining. Applied Microbiology and Biotechnology. 91(2): 237-249.

7 Environmental Protection Agency (EPA). 2008. EPA registers copper-containing alloy products. Available at $<$ http:// www.epa.gov/pesticides/factsheets/copper-alloy-products.htm>. [Accessed online in September 2018].

8 Gehan Z.M. 2009. A New Approach to evaluate the hygienic condition of commercial hatcheries. International Journal of Poultry Science. 8(11): 1047-1051.

9 Grass G., Rensing C. \& Solioz M. 2011. Metallic copper as an antimicrobial surface. Applied Environmental Microbiology. 77(5): 1541-1547.

10 Hayretda S. \& Kolankaya D. 2006. Investigation of the effects of pre-incubation formaldehyde fumigation on the tracheal epithelium of chicken embryos and chicks. Turkish Journal of Veterinary and Animal Sciences. 32(4): 263-267.

11 Keïta A., Huneau-Salaün A., Guillot A., Galliot P., Tavares M. \& Puterflam J. 2016. A multi-pronged approach to the search for an alternative to formaldehyde as an egg disinfectant without affecting worker health, hatching, or broiler production parameters. Poultry Science. 95(7): 1609-1616.

12 Kim J.H. \& Kim K.S. 2010. Hatchery hygiene evaluation by microbiological examination of hatchery samples. Poultry Science. 89(7): 1389-1398.

13 Luo J., Hein H., Mücklich F. \& Solioz M. 2017. Killing of bacteria by copper, cadmium, and silver surfaces reveals relevant physicochemical parameters. Biointerphases. 12(2): 1-6.

14 Martelli F., Birch C. \& Davies R.H. 2016. Observations on the distribution and control of Salmonella in commercial duck hatcheries in the UK. Avian Pathology. 45(2): 261-266. 
15 Michels H.T., Wilks S.A., Noyce J.O. \& Keevil C.W. 2005. Copper alloys for human infectious disease control. In: Proceedings of Materials Science and Technology Conference. (Pittsburgh, USA). Available at <http://citeseerx.ist. psu.edu/viewdoc/download?doi=10.1.1.559.9650\&rep=rep1\&type=pdf $>$. [Accessed online in August 2019].

16 Muraroli A. \& Mendes A.A. 2003. Manejo da incubação, transferência e nascimento do pinto. In: Macari M. \& Gonzales E. (Eds). Manejo da Incubação. 2.ed. Campinas: FACTA Ltda., pp.188-189.

17 Northcutt J.K. \& Berrang M.E. 2006. Influence of a chicken transport cage-washing system on wastewater characteristics and bacteria recovery from cage flooring. Journal of Applied Poultry Research. 15(3): 457-463.

18 Noyce J.O., Michels H. \& Keevil C.W. 2006. Potential use of copper surfaces to reduce survival of epidemic methicillinresistant Staphylococcus aureus in the healthcare environment. The Journal of Hospital Infection. 63(3): $289-297$.

19 Parra A., Toro M., Jacob R., Navarrete P., Troncoso M., Figueroa G. \& Reyes-Jara A. 2018. Antimicrobial effect of copper surfaces on bacteria isolated from poultry meat. Brazilian Journal of Microbiology. 49(1): 113-118.

20 Salthammer T., Mentese S. \& Marutzky R. 2010. Formaldehyde in the indoor environment. Chemical Reviews. 110(4): 2536-2572.

21 Samberg Y. \& Meroz M. 1995. Application of disinfectants in poultry hatcheries. Revue Scientifique et Techniqueoffice International des Epizooties. 14(2): 365-380.

22 Vincent M., Hartemann P. \& Engels-Deutsch M. 2016. Antimicrobial applications of copper. International Journal of Hygiene and Environmental Health. 219(7): 585-591.

23 Warren C.A., Weber S.K. \& Crespo R. 2016. Comparison of conventional plating methods and Petrifilm ${ }^{\mathrm{TM}}$ for the recovery of aerobic bacteria and mold from hatchery fluff samples. Journal of Applied Poultry Research. 25(1): 48-53. 